\title{
Quantification of Chemical Characteristics of Olive Fruit and Oil of cv Cobrançosa in Two Ripening Stages Using MIR Spectroscopy and Chemometrics
}

\author{
Manuela Machado • Nelson Machado • Irene Gouvinhas • \\ Maria Cunha • José M. M. M. de Almeida • \\ Ana I. R. N. A. Barros
}

Received: 30 June 2014 / Accepted: 7 October 2014 / Published online: 5 November 2014

(C) Springer Science+Business Media New York 2014

\begin{abstract}
The phenolic compound concentration of olives and olive oil is typically quantified using HPLC; however, this process is expensive and time consuming. The purpose of this work was to evaluate the potential of Fourier transform infrared (FTIR) spectroscopy combined with chemometrics, as a rapid tool for the quantitative prediction of phenol content and antioxidant activity in olive fruits and oils from "Cobrançosa" cultivar. Normalized spectral data using standard normal variate (SNV) and first and second SavitzkyGolay derivatives were used to build calibration models based on principal component regression (PCR) and on partial least squares regression (PLS-R), the performance of both models have been also compared. It was shown the possibility of establishing optimized regression models using the combined frequency regions of 3050-2750 and 1800-790 $\mathrm{cm}^{-1}$ instead of the full mid-infrared spectrum was shown. It was concluded that, in general, the first derivative of data and PLS-R models offered enhanced results. Low root-mean-square error (RMSE) and high correlation coefficients $\left(R^{2}\right)$ for the calibration and for the validation sets were obtained.
\end{abstract}

M. Machado • I. Gouvinhas • M. Cunha • A. I. R. N. A. Barros ( $₫)$ Chemistry Department, School of Life Sciences and Environment, University of Trás-os-Montes and Alto Douro, 5001-801 Vila Real, Portugal

e-mail: abarros@utad.pt

URL: http://www.utad.pt

J. M. M. M. de Almeida

INESC Porto, Rua do Campo Alegre 687, 4169-007 Porto, Portugal

J. M. M. M. de Almeida

Department of Physics, School of Sciences and Technology,

University of Trás-os-Montes and Alto Douro, 5001-801 Vila Real, Portugal

M. Machado - N. Machado - I. Gouvinhas - A. I. R. N. A. Barros CITAB, University of Trás-os-Montes and Alto Douro, 5001-801 Vila Real, Portugal
Keywords Chemometrics · Chemical composition · Olive oil antioxidant activity $\cdot$ Olive fruit antioxidant activity $\cdot$ Ripening stage $\cdot$ FTIR

\section{Introduction}

Quality assessment of raw food products and after transformation is very important for maintaining high quality standards (Ruth et al. 2010). The overall quality of food products depends on various factors, such as their sensory characteristics and stability, nutritional properties, bacteriological and chemical safety, and authenticity (Ruth et al. 2010).

The quality of olive fruits and olive oils depends on many factors, such as the cultivar, agricultural practices, environmental conditions, and the ripening stages (Kalua et al. 2005; Amaral et al. 2010; Bosque-Sendra et al. 2010).

It is known that during the maturation period, important changes occur in the chemical composition of the olive fruits. The amount of olive oil increases as the maturation develops, reaching its maximum during the maturation phase (Salvador et al. 2001). However, the oleic and palmitic acid concentrations decrease in the final stages of ripening, while on the other hand, the concentration of linoleic acid increases (Baccouri et al. 2008). The fruit maturation causes the reduction of the concentration in sterols and terpene hydrocarbons (Lukic et al. 2013). In terms of phenolic compounds, the total concentration of these compounds increases during the first stages of fruit ripening but decreases in the final stages (Kalua et al. 2005; Baccouri et al. 2008; Tovar et al. 2002; Morelló et al. 2005; Machado et al. 2013). The oleuropein concentration suffers a reduction during the maturation phases, leading to less spicy and duller flavored olive oil (Matos et al. 2007).

Throughout the maturation, the reduction of tocopherols also occurs, affecting the antioxidant properties of oil. 
Consequently, an early harvest leads to olive oils with better sensory attributes and oxidative stability (Matos et al. 2007).

In Portugal, the Trás-os-Montes region is the second largest olive production area in the country. "Cobrançosa" is one of the main cultivars of Trás-os-Montes, representing up to $30 \%$ of the olive cultivars, being mainly used for olive oil production (Machado et al. 2013). Comparing this cultivar with other Portuguese cultivars such as Picual and Galega, it can be readily observed that this cultivar has a different behavior during the ripening. The Cobrançosa cultivar presents a significant decrease in phenolic content during the maturation, particularly from the semi-ripe to ripe stage. Another interesting characteristic from this cultivar presents the highest content of flavonoids when compared with other cultivars (Barros et al. 2013).

The versatility, simplicity, and speed of the Fourier transform infrared-attenuated total reflection (FTIR-ATR) technique make it a very attractive analytical tool, being one of the most common spectroscopic techniques used in research laboratories and in the industry (Romera-Fernández et al. 2012; Rohman and Che Man 2012). It has been employed as a rapid tool for the identification and quantification of relevant compounds in food products, namely in meat, fish, beer, and fruit juices, among others (Karoui et al. 2010; Lachenmeir 2007; Duarte et al. 2002).

The analysis of olive oils based on measurements on the near-infrared (NIR) and mid-infrared (MIR) spectral bands, such as the determination of the adulterations and identification of the geographical origin and cultivar, was reported recently (Tapp et al. 2003; Maggio et al. 2010; LermaGarcia et al. 2010). Determination of biochemical parameters, such as fat acids, peroxide values, acidity, phenolic and volatile compounds, freshness, and oxidized fat acids, was also described (Nunes et al. 2009; Dupuy et al. 2010; Sinelli et al. 2010; Maggio et al. 2009; Sinelli et al. 2007).

The principal component regression (PCR) and the partial least squares regression (PLS-R) methods are well-known statistical methods, often used in quantitative prediction methodologies based on spectroscopic data (Wold et al. 2001; Jorgensen et al. 2004; Rohman and Che Man 2010). Both of these methods are based on reduction of data dimensionality and inverse calibration, in systems where there is a possibility to calibrate for the desired component while implicitly modeling the other source of variation (Wentzell et al. 2003; Rohman and Che Man 2010).

In the present work, the FTIR-ATR technique combined with PCR and PLS regression methods was used to build quantitative models of the variation of total phenols, orthodiphenols, flavonoids, and antioxidant activity of $\mathrm{cv}$ "Cobrançosa" olive fruits and of the respective oils in two ripening stages. These multivariate techniques could offer better accuracy and precision in substantially less time than classical data analysis methods. To the best of our knowledge, this is the first attempt to use mid-infrared spectroscopy along with multivariate regression methods for estimating biochemical characteristics of cv Cobrançosa olive fruits and of the respective oils.

Furthermore, the use of both PCR and PLS will allow the comparison of the performance of both models, therefore, allowing the assessment of the most suitable for this kind of work.

\section{Material and Methods}

\section{Sampling}

The work is based on six different clones of Cobrançosa olive cultivar, maintained by the Direção Regional de Agricultura e Pescas do Norte (DRAPN), Ministry of Agriculture and Sea, in a clonal field in Mirandela, Portugal.

Healthy olive fruits, without any kind of infection or physical damage, were collected. Samples representative of each clone were picked from ten different trees of comparable age and vigor and located in distinct points of the same growing area. Fruits were collected in two ripening stages: semi-ripe and ripe.

For the classification of the maturity index, the olives were evaluated according to their skin and pulp color (Uceda and Hermoso 1998). The ripeness index (RI) values range from 0 (100\% intense green skin) to 7 (100\% purple flesh and black skin). The semi-ripe samples $(\mathrm{RI}=2.5$, green skin with reddish spots) were collected in October (14 October 2011), and the ripe samples $(\mathrm{RI}=6$, black skin with $>50 \%$ purple flesh) were harvested in November ( 8 November 2011). After harvesting, the olive fruits were immediately transported to the laboratory and stored at $-20{ }^{\circ} \mathrm{C}$ until analysis.

The six genetically different Cobrançosa clones (Martins-Lopes et al. 2009) were chosen in accordance with previous studies (Sousa et al. 2014) once the chemical composition and organoleptic characteristics of olive and olive oils may be influenced by genotype and some agronomic factors like olive drupe harvesting date. Thus, olive fruits and olive oil from the six different Cobrançosa clones, which were harvested at two different ripening stages in the same olive-growing area, have been analyzed to evaluate phenolic compounds, ortho-diphenols, flavonoids, and antioxidant activity.

These clones have also been classified according to the yield of production: two were identified with high antioxidant activity and high yield ( $\mathrm{HH}$; clones 80 and 85$)$, two clones were identified with high antioxidant activity and low yield (HL; clones 14 and 49), one clone was identified with low antioxidant activity and high yield (LH; clone 111), and one clone was identified with low antioxidant activity and low yield (LL; clone 110). 
The olive oil samples were prepared in the Instituto Nacional de Investigação Agrária (INIA I.P.), Elvas, Portugal. Three kilograms of fresh olive fruits was used for olive oil production, using an Abencor system (INIA I.P., Elvas, Portugal). The oil was separated by decanting and transferred into dark glass bottles and was stored in the dark at $4{ }^{\circ} \mathrm{C}$ until chemical analysis.

\section{Preparation of Olive Samples}

The olive samples were placed in a greenhouse at $60{ }^{\circ} \mathrm{C}$ for 1 week (to remove water). Before reading the spectra, the samples were frozen in liquid nitrogen and turned into a powder. The water content is represented in Table 1.

\section{Spectra Acquisition Methodology}

The acquisition of the infrared spectra of the olive oil and olive fruit samples was performed on a Unicam Infrared Spectrometer Research Series, equipped with a single- reflection ATR (Golden Gate) attachment. The equipment is connected to a computer and controlled by WinFirst Software v1.1.

The olive oil samples were placed directly on top of the ATR baseplate by pipetting a small drop $(\sim 1 \mu \mathrm{l})$. In the case of olive fruit samples, $0.1 \mathrm{~g}$ was placed on the crystal with a small spatula.

For each olive oil sample, six replicas were measured and ten replicas were analyzed for each olive fruit sample. For each replica (either of oil or of olive fruit), the absorption was measured twice and the corresponding spectra were averaged. Between replicas, the ATR base was carefully cleaned in situ by scrubbing with ethanol (99.9\%) and dried with soft tissue and a new reference air background spectrum was taken. Each spectrum was subtracted against its corresponding background spectrum.

The temperature of the crystal was kept at $40{ }^{\circ} \mathrm{C}$. All spectra were recorded from 4000 to $500 \mathrm{~cm}^{-1}$, co-adding 128 interferograms at a resolution of $4 \mathrm{~cm}^{-1}$, the collection time of each spectrum being approximately $4 \mathrm{~min}$.

Table 1 Chemical composition of olive fruits and olive oils of cv Cobrançosa in the two ripening stages

\begin{tabular}{|c|c|c|c|c|c|c|}
\hline Clone & $\begin{array}{l}\text { Ripening } \\
\text { stage }\end{array}$ & $\begin{array}{l}\text { Water content } \\
(\%)\end{array}$ & 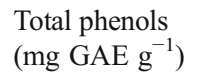 & $\begin{array}{l}\text { Ortho-diphenols } \\
\left(\mathrm{mg} \mathrm{GAE} \mathrm{g}^{-1}\right)\end{array}$ & $\begin{array}{l}\text { Flavonoids } \\
\left(\text { mg catechin } \mathrm{g}^{-1}\right)\end{array}$ & $\begin{array}{l}\text { Antioxidant activity } \\
\left(\mathrm{mmol} \text { trolox } \mathrm{kg}^{-1}\right)\end{array}$ \\
\hline \multicolumn{7}{|c|}{ Olive fruits } \\
\hline \multirow[t]{2}{*}{14} & Ripe & $49.49 \%$ & 33.96 & 40.02 & 26.15 & 119.89 \\
\hline & Semi-ripe & $50.60 \%$ & 22.30 & 32.51 & 13.92 & 103.50 \\
\hline \multirow[t]{2}{*}{49} & Ripe & $53.50 \%$ & 25.51 & 32.31 & 18.52 & 120.70 \\
\hline & Semi-ripe & $52.45 \%$ & 28.78 & 41.65 & 21.56 & 126.05 \\
\hline \multirow[t]{2}{*}{80} & Ripe & $55.00 \%$ & 30.32 & 40.76 & 17.96 & 130.57 \\
\hline & Semi-ripe & $54.60 \%$ & 29.72 & 33.49 & 19.27 & 138.87 \\
\hline \multirow[t]{2}{*}{85} & Ripe & $57.70 \%$ & 32.68 & 33.83 & 20.71 & 139.32 \\
\hline & Semi-ripe & $52.30 \%$ & 29.44 & 33.62 & 16.70 & 119.78 \\
\hline \multirow[t]{2}{*}{110} & Ripe & $63.00 \%$ & 21.78 & 15.84 & 7.24 & 72.14 \\
\hline & Semi-ripe & $46.60 \%$ & 16.95 & 13.61 & 5.09 & 56.59 \\
\hline \multirow[t]{2}{*}{111} & Ripe & $54.40 \%$ & 25.57 & 26.77 & 17.12 & 99.89 \\
\hline & Semi-ripe & $54.82 \%$ & 26.80 & 34.15 & 20.88 & 103.96 \\
\hline \multicolumn{7}{|c|}{ Olive oil } \\
\hline \multirow[t]{2}{*}{14} & Ripe & & 1.41 & 0.77 & 1.65 & 5.89 \\
\hline & Semi-ripe & & 1.33 & 0.63 & 1.45 & 5.19 \\
\hline \multirow[t]{2}{*}{49} & Ripe & & 1.46 & 0.82 & 1.70 & 6.54 \\
\hline & Semi-ripe & & 1.70 & 0.83 & 1.90 & 6.52 \\
\hline \multirow[t]{2}{*}{80} & Ripe & & 1.41 & 0.79 & 1.61 & 6.37 \\
\hline & Semi-ripe & & 1.72 & 0.82 & 1.96 & 7.49 \\
\hline \multirow[t]{2}{*}{85} & Ripe & & 0.94 & 0.54 & 1.46 & 4.38 \\
\hline & Semi-ripe & & 1.39 & 0.65 & 1.47 & 5.56 \\
\hline \multirow[t]{2}{*}{110} & Ripe & & 0.39 & 0.40 & 0.65 & 2.67 \\
\hline & Semi-ripe & & 0.74 & 0.37 & 0.78 & 3.01 \\
\hline \multirow[t]{2}{*}{111} & Ripe & & 0.97 & 0.59 & 1.20 & 4.49 \\
\hline & Semi-ripe & & 1.11 & 0.53 & 1.20 & 4.63 \\
\hline
\end{tabular}

From Sousa et al. 2014 


\section{Mathematical Treatment of Dataset}

Both PCR and PLS regression methods are utilized to model a response variable when a biological system is analyzed through a large number of predictor variables that are highly correlated or even collinear (Miller and Miller 2005). Both methods give rise to new predictor variables, usually known as principal components (PCs) or latent variables that are linear combinations of the original predictor variables (Miller and Miller 2005). Those components are calculated in different ways, and PCR creates PCs to explain the observed variability in the predictor variables, without considering the response variable. In PLS-R, the response variable is taken into account and, consequently, leads to models that can fit the response variable with fewer factors (Wold et al. 2001; Wentzell et al. 2003).

\section{Treatment of Spectral Data}

Prior to pre-treatment and statistical analysis of spectral data, each spectrum was divided into two regions: a first region from 3050 to $2750 \mathrm{~cm}^{-1}$ and a second from 1800 to $600 \mathrm{~cm}^{-1}$. The spectral regions not utilized were very noisy and did not correspond to any functional group of interest. Spectral pre-treatments of the raw spectral data included the following: auto-baseline and smoothing followed by standard normal variate (SNV) (Nunes et al. 2009; Bendini et al. 2007a) and the first and second Savitzky-Golay derivatives (Bendini et al. 2007a). Multivariate analysis was performed with XLSTAT-v2006.06 package (Addinsoft, Inc.).

\section{Model Selection}

In the PLS-R and PCR calibration models, the evaluation of the model linearity was carried out in order to show a proportional relationship between predictor variables (absorbencies) and the biochemical characteristics of olives (Table 1), such as the concentration of total phenols, ortho-diphenols and flavonoids and antioxidant activity.

The quality of the fitting was scrutinized by the rootmean-square error of calibration (RMSEC), multiple coefficient of determination or regression coefficient $\left(R^{2}\right.$, where $R$ is the correlation factor), and root-mean-square error of cross-validation (RMSECV). The optimum number of factors either for the PLS-R or PCR models was determined using leave-one-out (LOO) cross-validation method. The optimal number of factors is the one that minimizes the RMSECV.

The PLS regression method is able to collect information from large spectral intervals, correlating changes therein to the concentration of specific constituents, while concomitantly considers other possible contribution to these changes not related to the sample constitution (Che Man et al. 2005). On the other way, in the PCR method, the spectral and concentration information are incorporated into the model in different steps (Smith 2002). Generically, PCR is divided in two steps, firstly the principal component analysis and secondly the regression (Smith 2002; Xie and Kalivas 1997).

Measurement of Chemical Parameters

The values of the total phenols, ortho-diphenols, flavonoids, and antioxidant activity, necessary to the elaboration of the present work, were measured previously by the authors, and the results were published elsewhere (Sousa et al. 2014). Table 1 presents the corresponding values for olive fruits and oils.

\section{Results and Discussion}

\section{Absorption Spectra}

Infrared spectroscopy allows the identification of molecular structures through the assignment of certain absorption bands to particular functional groups. In edible oils and fats, most of the peaks of the spectrum are related to specific functional groups (Bendini et al. 2007b). The triglycerides are the principal components in edible oils and fats and, therefore, dictate the spectra.

Figure 1 illustrates measured FTIR spectra (after smoothing and baseline correction) of Cobrançosa (clone 80) olive oil in the mid-infrared region $\left(3100-550 \mathrm{~cm}^{-1}\right)$ in both ripening stages.

In relation to the ripening stage from the analysis of FTIR spectra, we verify that there are no changes in the frequencies of the functional groups. However, the absorbance of each functional group varies according to the ripening stage. In general, the absorbance of the functional group associated to the ester group $(\mathrm{C}=\mathrm{O})$ is greatest in the ripening stage. The increase in the absorption value of the ester group in this ripening stage may be associated with an increase of fat content during maturation. It is known that the fat content increases during the fruit development and reaches its maximum in very ripe fruits (Salvador et al. 2001). There is also a decrease in the absorbance value for the frequencies 1234, 1160,1118 , and $1099 \mathrm{~cm}^{-1}$ (Safar et al. 1994). These frequencies are related to the stretching vibration of the $-\mathrm{C}-\mathrm{O}-$ group; this group may come from either fatty acids or phenolic compounds (Kuligwski et al. 2010). Even though the variation of the absorption value in this group could be related either to the changes in phenol content or to the differences respecting the fat content, in the final stage of maturation, these variations 
Fig. 1 Example of FTIR-ATR spectra collected and the first/ second derivatives: olive oil from clone 80 in the ripening and semiripening stages

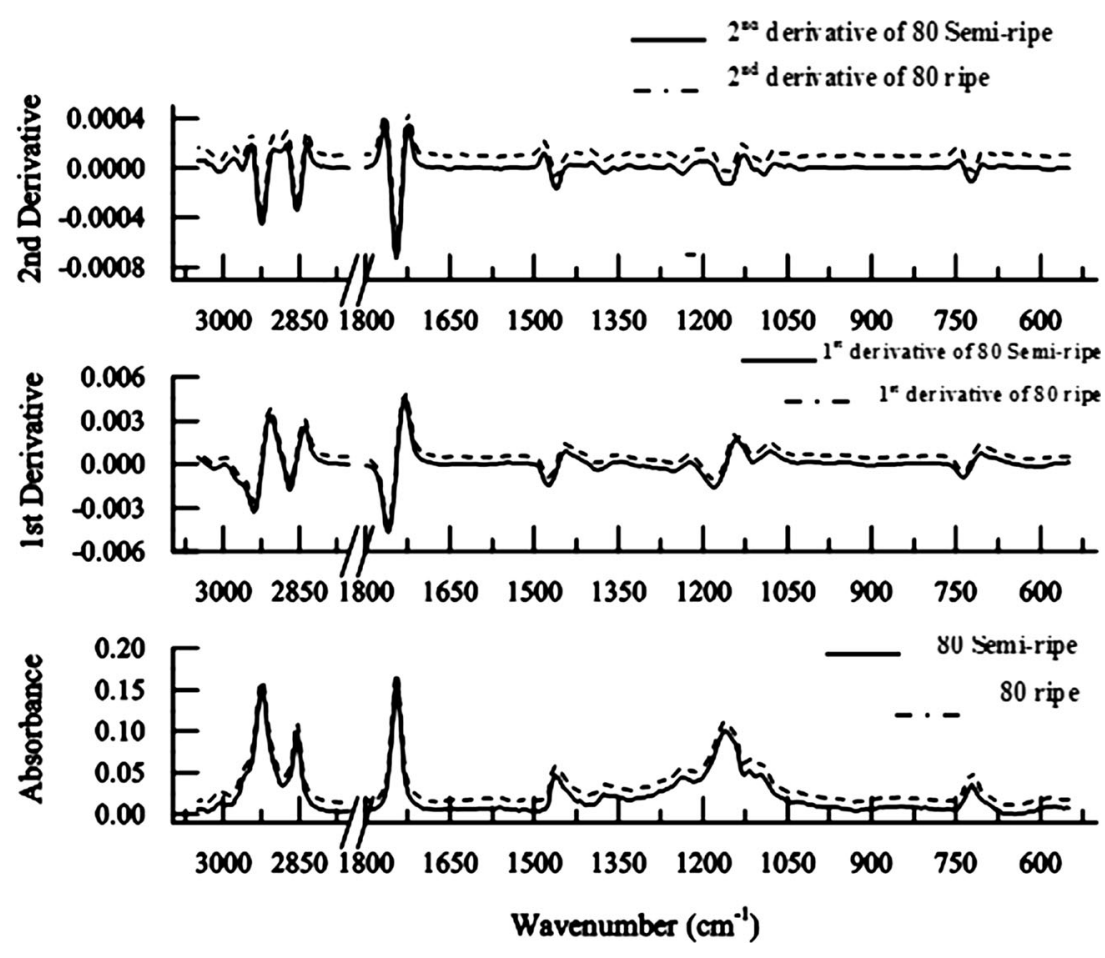

Table 2 Olive fruits: PLS-R and PCR multivariate calibrations for quantification of chemical composition

\begin{tabular}{|c|c|c|c|c|c|c|c|}
\hline \multirow[t]{2}{*}{ Chemical parameter } & \multirow[t]{2}{*}{ Regression method } & \multirow[t]{2}{*}{ Spectra } & \multirow[t]{2}{*}{ Number of factors } & \multicolumn{2}{|l|}{$R^{2}$} & \multirow[t]{2}{*}{ RMSEC (\%) } & \multirow[t]{2}{*}{ RMSECV (\%) } \\
\hline & & & & Calibration & Validation & & \\
\hline \multirow[t]{6}{*}{ Total phenols } & \multirow[t]{3}{*}{ PLS-R } & Normal & 3 & 0.993 & 0.981 & 5.61 & 6.12 \\
\hline & & First der & 2 & 0.995 & 0.931 & 3.44 & 3.95 \\
\hline & & Second der & 4 & 0.982 & 0.892 & 12.47 & 19.41 \\
\hline & \multirow[t]{3}{*}{ PCR } & Normal & 4 & 0.991 & 0.891 & 5.16 & 5.95 \\
\hline & & First der & 4 & 0.998 & 0.952 & 3.77 & 4.69 \\
\hline & & Second der & 4 & 0.910 & 0.871 & 12.44 & 20.16 \\
\hline \multirow[t]{6}{*}{ Ortho-diphenols } & \multirow[t]{3}{*}{ PLS-R } & Normal & 3 & 0.993 & 0.990 & 6.21 & 7.12 \\
\hline & & First der & 3 & 0.995 & 0.991 & 4.95 & 5.54 \\
\hline & & Second der & 3 & 0.980 & 0.950 & 17.71 & 19.51 \\
\hline & \multirow[t]{3}{*}{ PCR } & Normal & 4 & 0.989 & 0.984 & 6.92 & 7.37 \\
\hline & & First der & 4 & 0.992 & 0.989 & 6.18 & 6.99 \\
\hline & & Second der & 4 & 0.970 & 0.931 & 13.78 & 17.85 \\
\hline \multirow[t]{6}{*}{ Flavonoids } & \multirow[t]{3}{*}{ PLS-R } & Normal & 3 & 0.997 & 0.987 & 4.13 & 4.89 \\
\hline & & First der & 2 & 0.995 & 0.986 & 3.51 & 3.72 \\
\hline & & Second der & 3 & 0.991 & 0.989 & 14.26 & 19.23 \\
\hline & \multirow[t]{3}{*}{ PCR } & Normal & 3 & 0.984 & 0.980 & 2.91 & 4.23 \\
\hline & & First der & 3 & 0.989 & 0.984 & 1.85 & 2.65 \\
\hline & & Second der & 4 & 0.971 & 0.974 & 10.14 & 15.55 \\
\hline \multirow[t]{6}{*}{ Antioxidant activity } & \multirow[t]{3}{*}{ PLS-R } & Normal & 3 & 0.975 & 0.970 & 7.14 & 8.91 \\
\hline & & First der & 3 & 0.986 & 0.979 & 8.28 & 7.99 \\
\hline & & Second der & 4 & 0.955 & 0.946 & 15.12 & 18.83 \\
\hline & \multirow[t]{3}{*}{ PCR } & Normal & 4 & 0.976 & 0.969 & 6.89 & 7.95 \\
\hline & & First der & 4 & 0.988 & 0.980 & 7.25 & 8.26 \\
\hline & & Second der & 4 & 0.938 & 0.887 & 16.99 & 20.64 \\
\hline
\end{tabular}


do not present any trend that might be related to the content variation of specific components. Additionally, although several studies have demonstrated that in final stages of fruit ripening, the phenolic content decreases due to the reduction on its biosynthesis (Sousa et al. 2014; Machado et al. 2013; Barros et al. 2013; Morelló et al. 2005; Tovar et al. 2002), in the present work, some clones have shown not to follow this trend (Table 1), leading the establishment of reliable correlations between specific spectral variations and phenolic content to be a troublesome task.

\section{Models for Prediction of Chemical Parameters Using FTIR}

The results achieved for the PLS-R and PCR calibrations of total phenols, ortho-diphenols, flavonoids, and antioxidant activity in terms of $R^{2}$, RMSEC, and RMSECV, either for normal spectra, from 3050 to $2750 \mathrm{~cm}^{-1}$ and from 1800 to $600 \mathrm{~cm}^{-1}$, or for their first and second derivatives, are presented in Table 2 for olive fruits and in Table 3 for olive oil.

For all the chemical parameters under analysis, the multivariate calibrations showed, in general, the highest value of $R^{2}$ and the lowest of RMSECV when using the first derivative of the spectral data. Also, in the present work, PLS-R appeared to perform better than PCR, presenting lower errors for the same analyses.

The relationship between measured values of the chemical parameters and the FTIR-predicted values for olive fruits showed $R^{2}$ values ranging from 0.910 to 0.998 using the calibration set and from 0.871 to 0.991 when cross validated. For olive oils, the corresponding values ranged from 0.910 to 0.999 using the calibration set and from 0.889 to 0.990 when cross validated.

For olive fruits, the lowest RMSECV (2.65\%) for the flavonoid concentration was found when using the first derivative and a PCR model with three factors. However, a slightly higher RMSECV value of $3.72 \%$ was attained for a simpler two-factor PLS-R model. For olive oils, the lowest RMSECV value was $3.81 \%$ for the flavonoid concentration, when using the normal spectra and the PCR method with four factors. As for olive fruits, a somewhat higher RMSECV value of $5.82 \%$ was achieved for a two-factor PLS-R model when using the first

Table 3 Olive oil: PLS-R and PCR multivariate calibrations for quantification of chemical composition

\begin{tabular}{|c|c|c|c|c|c|c|c|}
\hline \multirow[t]{2}{*}{ Chemical parameter } & \multirow[t]{2}{*}{ Regression method } & \multirow[t]{2}{*}{ Spectra } & \multirow[t]{2}{*}{ Number of factors } & \multicolumn{2}{|l|}{$R^{2}$} & \multirow[t]{2}{*}{ RMSEC (\%) } & \multirow[t]{2}{*}{ RMSECV (\%) } \\
\hline & & & & Calibration & Validation & & \\
\hline \multirow[t]{6}{*}{ Total phenols } & \multirow[t]{3}{*}{ PLS-R } & Normal & 2 & 0.962 & 0.951 & 5.13 & 5.04 \\
\hline & & First der & 2 & 0.951 & 0.921 & 3.10 & 4.94 \\
\hline & & Second der & 3 & 0.940 & 0.890 & 16.47 & 23.06 \\
\hline & \multirow[t]{3}{*}{ PCR } & Normal & 3 & 0.991 & 0.990 & 6.45 & 6.99 \\
\hline & & First der & 3 & 0.992 & 0.952 & 4.52 & 5.39 \\
\hline & & Second der & 4 & 0.910 & 0.940 & 13.47 & 14.82 \\
\hline \multirow[t]{6}{*}{ Ortho-diphenols } & \multirow[t]{3}{*}{ PLS-R } & Normal & 3 & 0.990 & 0.988 & 5.90 & 9.48 \\
\hline & & First der & 2 & 0.994 & 0.988 & 5.18 & 8.05 \\
\hline & & Second der & 3 & 0.980 & 0.959 & 15.50 & 17.91 \\
\hline & \multirow[t]{3}{*}{ PCR } & Normal & 3 & 0.989 & 0.988 & 6.34 & 7.69 \\
\hline & & First der & 3 & 0.993 & 0.985 & 6.96 & 8.64 \\
\hline & & Second der & 4 & 0.970 & 0.930 & 9.30 & 24.81 \\
\hline \multirow[t]{6}{*}{ Flavonoids } & \multirow[t]{3}{*}{ PLS-R } & Normal & 3 & 0.999 & 0.988 & 5.78 & 6.16 \\
\hline & & First der & 2 & 0.998 & 0.987 & 4.39 & 5.28 \\
\hline & & Second der & 4 & 0.990 & 0.990 & 16.91 & 17.05 \\
\hline & \multirow[t]{3}{*}{ PCR } & Normal & 4 & 0.983 & 0.979 & 3.20 & 3.81 \\
\hline & & First der & 4 & 0.984 & 0.981 & 3.93 & 4.55 \\
\hline & & Second der & 4 & 0.970 & 0.970 & 7.75 & 7.75 \\
\hline \multirow[t]{6}{*}{ Antioxidant activity } & \multirow[t]{3}{*}{ PLS-R } & Normal & 3 & 0.984 & 0.981 & 5.00 & 6.47 \\
\hline & & First der & 2 & 0.993 & 0.979 & 4.28 & 5.79 \\
\hline & & Second der & 4 & 0.950 & 0.942 & 11.09 & 14.92 \\
\hline & \multirow[t]{3}{*}{ PCR } & Normal & 4 & 0.976 & 0.969 & 6.48 & 7.73 \\
\hline & & First der & 3 & 0.988 & 0.980 & 6.16 & 7.37 \\
\hline & & Second der & 4 & 0.931 & 0.889 & 17.65 & 18.74 \\
\hline
\end{tabular}


derivative. In fact, in the present work, where a large number of samples is not available, the PLS approach seemed to be more suitable for this kind of studies, generally presenting a better performance than PCR.

The plot of the measured concentrations of the chemical components against the FTIR-predicted values reveals a fairly good correlation between predicted and actual values. To illustrate the reliability of the models proposed in this work, PLS-R calibrations are presented in Fig. 2 for flavonoid and total phenol concentrations of olive fruits and in Fig. 3 for ortho-diphenol concentration and antioxidant activity of olive fruits.

PLS regression method has the capability to use information from a wide spectral frequency range and then correlate spectral absorption change with concentration of chemical parameters while at the same time compute other spectra which may disturb spectral analysis (Che Man et al. 2005). On the other way, in the PCR method, the spectral and concentration information is incorporated into the model in one step (Smith 2002).

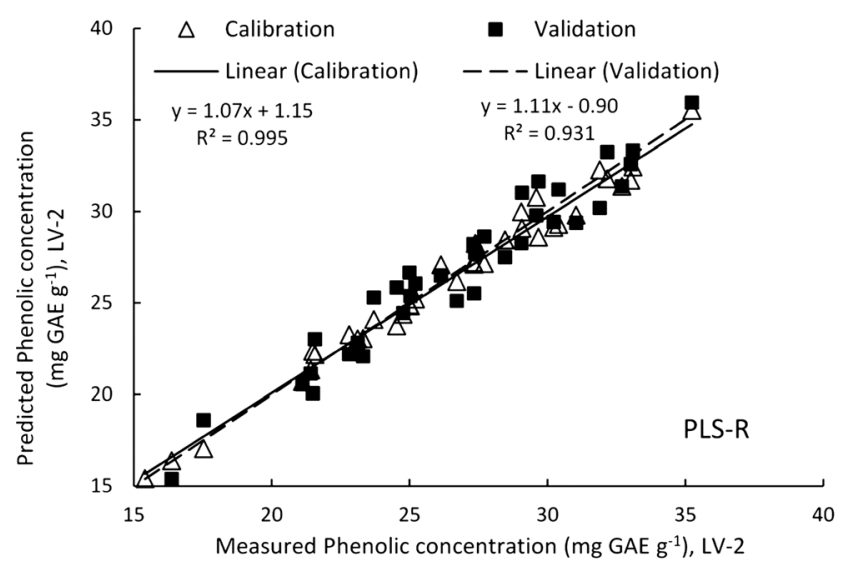

a)

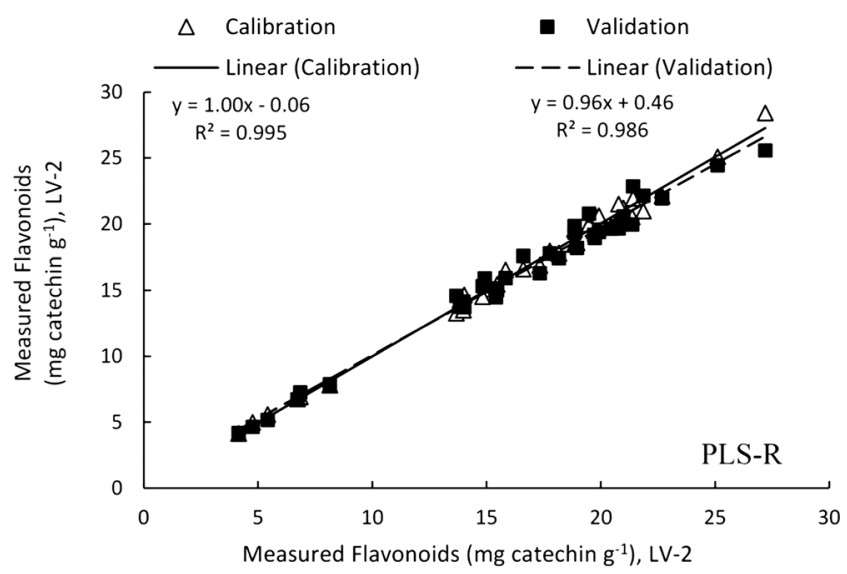

b)

Fig. 2 PLS-R calibration models for the relationship between measured values and FTIR-predicted values of $\mathbf{a}$ total phenol and $\mathbf{b}$ flavonoid concentrations of olive fruits

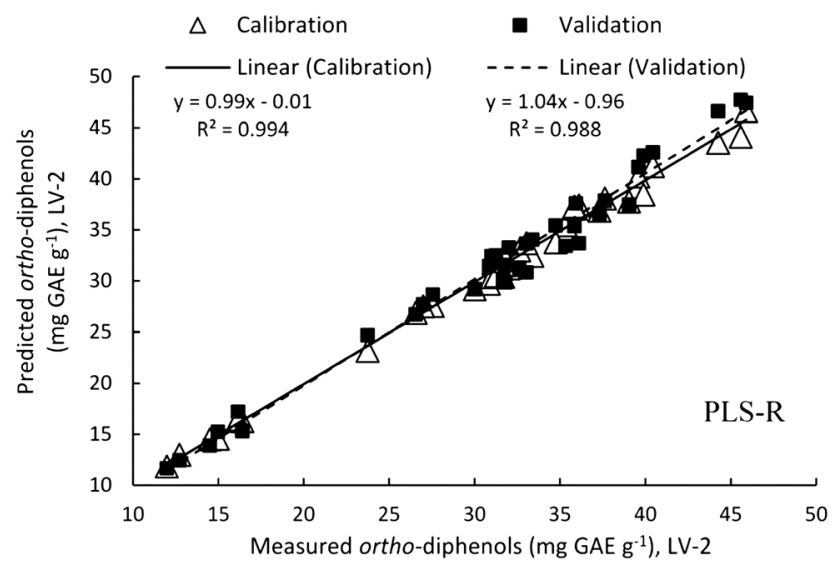

a)

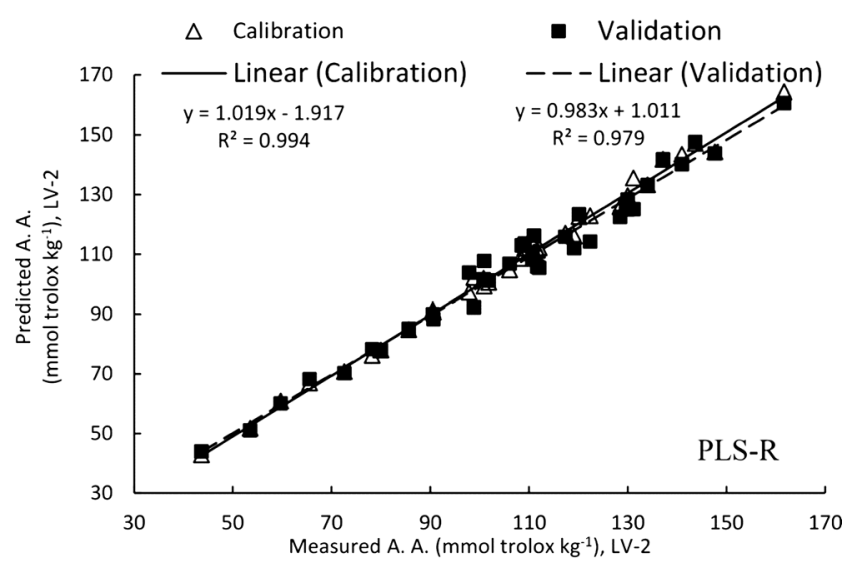

b)

Fig. 3 PLS-R calibration models for the relationship between measured values and FTIR-predicted values of a ortho-diphenol concentration and b antioxidant activity of olive fruits

\section{Conclusions}

Taking into account the results obtained, we can conclude that the FTIR-ATR technique in tandem with multivariate analysis, namely the principal component regression and the partial least squares regression, can provide a rapid methodology to assess the chemical composition of olives and olive oils.

In both methods, we obtain high $R^{2}$ values and low values of RMSECV; however, the PLS-R using the first derivate gives better results. The $R^{2}$ for the results of olive fruit varied from 0.93 to 0.99 , and RMSECV varied between 3.72 and $7.99 \%$. In relation to the olive oil, the coefficient of determination varied from 0.92 to 0.98 and the RMSECV from 4.94 to $8.05 \%$. With this result, we can affirm that the mathematic models chosen are appropriate to predict the concentration of phenolic compounds and the antioxidant activity of olives, besides the complexity of the matrix. 
Several studies have been previously undertaken, with resort to this methodology, with the view or assessing distinct physico-chemical parameters; geographical origin; and distinct cultivars for olive oil, olives, and other fruits and different kinds of foodstuff. With the present study, the applicability of this approach, FTIR coupled to multivariate analysis, has now been extended for the study of different clones from the same cultivar and species.

Finally, it can be concluded that this methodology shows a high potential for determining the chemical composition of olive oil and olives in the real time, due to its reliability, and simplicity of the FTIR-ATR experimental setup.

Acknowledgments This work was supported by the Project $\mathrm{PhD}$ grant SFRH/BD/78013/2011 to IG from the Fundação para a Ciência e a Tecnologia.

This work is financed by the European Regional Development Fund (ERDF) through the COMPETE Programme (Operational Programme for Competitiveness) and by National Funds through the Fundação para a Ciência e a Tecnologia (FCT) (Portuguese Foundation for Science and Technology) within project FCOMP-01-0124-FEDER-037281.

This work is supported by national funds by FCT - Portuguese Foundation for Science and Technology, under the project PEst-OE/AGR/ UI4033/2014 and Project INNovation in the FOOD (INNOFOOD) sector through the valorization of food and agro-food by-products (NORTE-070124-FEDER-0000029), financed by the North Portugal Regional Operational Programme (ON.2 - O Novo Norte) under the National Strategic Reference Framework (QREN), through FEDER, as well as by PIDDAC through FCT/MEC.

Compliance with Ethics Requirements Manuela Machado has no conflict of interest. Nelson Machado has no conflict of interest. Irene Gouvinhas has no conflict of interest. Maria Cunha has no conflict of interest. José Almeida has no conflict of interest. Ana Barros has no conflict of interest. This article does not contain any studies with human or animal subjects.

\section{References}

Amaral SJ, Mafra I, Oliveira MBP (2010) In: Olives and olive oil in health and disease prevention. Victor R. Preedy and Ronald Ross Watson (eds). Academic Press, Oxford

Baccouri O, Guerfel M, Baccouri B, Cerratani L, Bendini A, Lercker G, Zarrouck M, Miled DDB (2008) Chemical composition and oxidative stability of Tunisian monovarietal virgin olive oils with regard to fruit ripening. Food Chem 109:743-754

Barros A I, Freire I, Gonçalves B, Bacelar E, Gomes S, Lopes J, GuedesPinto H, Martins-Lopes P (2013) Evaluation of chemical and phenotipic changes in Blanqueta, Cobrançosa and Galega during olive fruits ripening. Cyta 11:136-141

Bendini A, Cerretani L, Di Virgilio F, Belloni P, Bonoli-Carbognin M, Lercker G (2007) Preliminary evaluation of the application of the FTIR spectroscopy to control the geographic origin and quality of virgin olive oil. J Food Quality 30(4):424 437. doi:10.1111/j.17454557.2007.00132.x

Bendini A, Cerretani L, Virgilio F, Belloni P, Lercker G, Toschi TG (2007b) In-process monitoring in industrial olive mil by means of FT-NIR. Eur J Lipid Sci Technol 109:498-504

Bosque-Sendra JM, Cuadros-Rodriguez L, Chiavaro E, Kaufman T, Bendini A (2010) Combining chromatography and chemometrics for the characterization and authentication of fats and oils from triacylglycerol compositional data - a review. Anal Chim Acta 724:1-11

Che Man YB, Syahariza ZA, Mirghani MES, Jinap S, Bakar J (2005) Analysis of potential lard adulteration in chocolate and chocolate products using Fourier transform infrared spectroscopy. Food Chem 90:815-819

Duarte I, Barros A, Delgadillo I, Almeida C, Gil A (2002) Application of FTIR spectroscopy for the quantification of sugars in mango juice as a function of ripening. J Agr Food Chem 50:3104-3111

Dupuy N, Galtier O, Ollivier D, Vanloot P, Artaud J (2010) Comparison between NIR, MIR, concatenated NIR and MIR analysis and hierarchical PLS model. Application to virgin olive oil analysis. Anal Chim Acta 666:23-31

Jorgensen K, Segtnan V, Thyholt K, Naes T (2004) A comparison of methods for analysing regression models with both spectral and designed variables. J. Chemometrics 18:451-461

Kalua CM, Allen MS, Bedgood DR, Bishop AG, Prenzler PD (2005) Discrimination of olive oils and fruit into cultivars and maturity stages based on phenolic and volatile compounds. J Agr Food Chem 53:8054-8062

Karoui R, Downey G, Blecker C (2010) Mid-infrared spectroscopy couple with chemometrics: a tool for the analysis of intact food systems and exploration of their molecular structure-quality relationships. A Review Chemical Rev 110:6144-6168

Kuligwski J, Quintás G, Garrigues S, Guardia M (2010) Direct determination of polymerized triglycerides in deep frying olive oil by attenuated total reflectance-Fourier transform infrared spectroscopy using partial least squares regression. Anal Bioanal Chem 397:861869

Lachenmeir D (2007) Rapid quality control of spirit drinks and beer using multivariate data analysis of Fourier transform infrared spectra. Food Chem 101:825-832

Lerma-Garcia M, Ramis-Ramos G, Herrero-Martinez JM, Simó-Alfonso EF (2010) Authentication of extra virgin olive oils by Fouriertransform infrared spectroscopy. Food Chem 118:78-83

Lukic M, Lukic I, Krapac M, Sladanja B, Plilizot V (2013) Sterols and triterpenic diols in olive oil as indicators of variety and degree of ripening. Food Chem 136:251-258

Machado M, Felizardo C, Fernandes-Silva AA, Nunes FM, Barros A (2013) Polyphenolic compounds, antioxidant activity and Lphenylalanine ammonia-lyase activity during ripening of olive $\mathrm{cv}$. "Cobrançosa" under different irrigation regimes. Food Res Int 51: 412-421

Maggio RM, Cerretani L, Chiavaro E, Kaufman TS, Bendini A (2010) A novel chemometric strategy for the estimation of extra virgin olive oil adulteration with edible oils. Food Control 21:890-895

Maggio RM, Kaufman T, Del Carlo M, Cerretani L, Bendini A, Cichelli A, Compagnone D (2009) Monitoring of fatty acid composition in virgin olive oil by Fourier transformed infrared spectroscopy couple with partial least squares. Food Chem 114:1549-1554

Martins-Lopes P, Gomes S, Lima-Brito J, Lopes J, Guedes-Pinto H (2009) Assessment of clonal genetic variability in Olea europaea L. 'Cobrançosa' by molecular markers. Sci Hortic 123:82-89

Matos LC, Cunha SC, Amaral JS, Pereira JA, Andrade PB, Seabra RM, Oliveira BPP (2007) Chemometric characterization of three varietal olive oils (cvs Cobrançosa, Madural and Verdeal Transmontana), extracted from olives with different maturation indices. Food Chem 102:406-414

Miller JN, Miller JC (2005) In: Statistics and Chemometrics for Analytical Chemisitry 5th Edition; Pearson Education Limited, Edinburgh Gate, Harlow, UK

Morelló JR, Romero MP, Ramo T, Motilva MJ (2005) Evaluation of Lphenylalanine ammonia-lyase activity and phenolic profile in olive drupe (Olea europaea L.) from fruit setting period to harvesting time. Plant Sci 168:65-72 
Nunes A, Martins J, Barros AS, Galvis-Sánchez AC, Delgadillo I (2009) Estimation of olive oil acidity using FT-IR and partial least squares regression. Sens Instrum Food Qual 3:187-191

Rohman A, Che Man YB (2010) Fourier transform infrared (FTIR) spectroscopy for analysis of extra virgin olive oil adulterated with palm oil. Food Res Int 43:886-892

Rohman A, Che Man YB (2012) The chemometrics approach applied to FTIR spectral data for the analysis of rice bran oil in extra virgin olive oil. Chemometr Intell Labo 110:129-134

Romera-Fernández M, Berruera LA, Garmón-Lobato S, Gallo B, Vicente F, Moreda JM (2012) Feasibility study of FT-MIR spectroscopy and PLS-R for the fast determination of anthocyanins in wine. Talanta 88:303-310

Ruth SM, Villegas B, Akkermans W, Rozign M, Kamp H, Koot A (2010) Prediction of the identity of fats and oils by their fatty acid, triacylglycerol and volatile compositions using PLS-DA. Food Chem 118: 48-955

Safar M, Bertrand D, Rober P, Devaux MF, Genot C (1994) Characterization of edible oils, butter and margarines by Fourier transform infrared spectroscopy with attenuated total reflectance. J Am Oil Chem Soc 71:371-377

Salvador MD, Aranda F, Fregapane G (2001) Influence of fruit ripening on "Cornicabra" virgin olive oil quality: a study of four successive crop seasons. Food Chem 73:45-53

Sinelli N, Cerretani L, Di Egidio V, Bendini A, Casiraghi E (2010) Application of near (NIR) infrared and mid (MIR) infrared spectroscopy as a rapid tool to classify extra virgin olive oil on basis of fruit attribute intensity. Food Res Int 43:369-367
Sinelli N, Cosio MS, Gigliotti C, Casiraghi E (2007) Preliminary study on application of mid infrared spectroscopy of the evaluation of the virgin olive oil "freshness". Anal Chim Acta 598:128-134

Smith BC (2002) Quantitative spectroscopy: theory and practice. Academic, Amsterdam, pp 125-179

Sousa C, Gouvinhas I, Barreira D, Carvalho MI, Vilela A, Lopes J, Martins-Lopes M, Barros AI (2014) 'Cobrançosa' olive oil and drupe: chemical composition in two ripening stages. J Am Oil Chem Soc 91(4): 599-611. doi: 10.1007/s11746-013-2406-x

Tapp HS, Defernez M, Kemsley K (2003) FTIR spectroscopy and multivariate analysis can distinguish the geographic origin of extra virgin olive oils. J Agr Food Chem 51:6110-6115

Tovar MJ, Romero MP, Girona J, Motilva MJ (2002) L-Phenylalanine ammonia-lyase activity and concentration of phenolics in developing olive (Olea europaea L. cv Arbequina) fruit grown under different irrigation regimes. J Sci Food Agr 82:892-898

Uceda M, Hermoso M (1998) La calidad del aceite de olive. In D. Barranco, R., Fernandez Escobar, L. Rallo (eds), El cultivo del olivo, Madrid, Spain: Junta de Andalucia Ediciones Mundi-Prensa, pp. 547-572

Wentzell PD, Montoto LV (2003) Comparison of principal components regression and partial least squares regression through generic simulations of complex mixtures. Chemometr. Intell. Lab. Systems 65: 257-279

Wold S, Sjostrom M, Erikson L (2001) PLS-regression: a basic toll of chemometrics. Chemometr Intel Lab 58:109-130

Xie Y-L, Kalivas JH (1997) Local prediction models by principal components regression. Anal Chim Acta 348:29-38. doi: 10.1016/ S0003-2670(97)00036-6 